\title{
Analysis of High-Altitude De-Acclimatization Syndrome after Exposure to High Altitudes: A Cluster-Randomized Controlled Trial
}

\author{
Binfeng He ${ }^{19}$, Jianchun Wang ${ }^{19}$, Guisheng Qian ${ }^{19}$, Mingdong $\mathrm{Hu}^{1}$, Xinming Qu ${ }^{1}, \mathrm{Zhenghua} \mathrm{Wei}^{1}$, Jin $\mathrm{Li}^{1}$, \\ Yan Chen ${ }^{1}$, Huaping Chen ${ }^{1}$, Qiquan Zhou ${ }^{2}$, Guansong Wang ${ }^{1 *}$
}

1 Institute of Respiratory Diseases, The Second Affiliated Hospital of the Third Military Medical University, Chongqing, China, 2 Department of High Altitude Diseases, College of High Altitude Military Medicine, Third Military Medical University, Chongqing, China

\begin{abstract}
The syndrome of high-altitude de-acclimatization commonly takes place after long-term exposure to high altitudes upon return to low altitudes. The syndrome severely affects the returnee's quality of life. However, little attention has been paid to careful characterization of the syndrome and their underlying mechanisms. Male subjects from Chongqing $(n=67,180 \mathrm{~m})$ and Kunming $(n=70,1800 \mathrm{~m})$ visited a high-altitude area $(3650 \mathrm{~m})$ about 6 months and then returned to low-altitude. After they came back, all subjects were evaluated for high-altitude de-acclimatization syndrome on the $3^{\text {rd }}, 50^{\text {th }}$, and $100^{\text {th }}$. Symptom scores, routine blood and blood gas tests, and myocardial zymograms assay were used for observation their syndrome. The results showed that the incidence and severity of symptoms had decreased markedly on the $50^{\text {th }}$ and $100^{\text {th }}$ days, compared with the $3^{\text {rd }}$ day. The symptom scores and incidence of different symptoms were lower among subjects returning to Kunming than among those returning to Chongqing. On the $3^{\text {rd }}$ day, RBC, Hb, Hct, CK, CK-MB, and LDH values were significantly lower than values recorded at high altitudes, but they were higher than baseline values. On the $50^{\text {th }}$ day, these values were not different from baseline values, but LDH levels did not return to baseline until the $100^{\text {th }}$ day. These data show that, subjects who suffered high-altitude de-acclimatization syndrome, the recovery fully processes takes a long time $\left(\geq 100^{\text {th }}\right.$ days). The appearance of the syndrome is found to be related to the changes in $R B C, H b, H c t, C K, C K-M B$, and LDH levels, which should be caused by reoxygenation after hypoxia.
\end{abstract}

Citation: He B, Wang J, Qian G, Hu M, Qu X, et al. (2013) Analysis of High-Altitude De-Acclimatization Syndrome after Exposure to High Altitudes: A ClusterRandomized Controlled Trial. PLoS ONE 8(5): e62072. doi:10.1371/journal.pone.0062072

Editor: Erik L. Ritman, Mayo Clinic College of Medicine, United States of America

Received November 7, 2012; Accepted March 18, 2013; Published May 1, 2013

Copyright: $\odot 2013 \mathrm{He}$ et al. This is an open-access article distributed under the terms of the Creative Commons Attribution License, which permits unrestricted use, distribution, and reproduction in any medium, provided the original author and source are credited.

Funding: This work was supported by the Ministry of Science and Technology of China 2009BAl85B03 (to QZ and GW) and grants 30971309 and 81170066 from National Science Foundation of China (NSFC) (to GW) and 80070067 from NSFC (to JW). The funders had no role in study design, data collection and analysis, decision to publish, or preparation of the manuscript.

Competing Interests: The authors have declared that no competing interests exist.

*E-mail: wanggs2003@hotmail.com

9 These authors contributed equally to this work.

\section{Introduction}

High-altitude de-acclimatization is a multifaceted process involving the loss of high-altitude acclimation over time after an individual who has acclimated to high altitudes returns to lower altitudes [1]. The changes in physiological functions experienced by explorers returning to sea level from high altitudes were documented as early as 1908 [2]. High-altitude de-acclimatization has been noted in explorers [3], athletes [4], military personnel [5], high-altitude railway workers [6], and workers in high-altitude mines [7]. Hypoxia is always considered the main threat to mammals at these altitudes, so high-altitude de-acclimatization is also considered de-acclimatization to hypoxia [1]. Over the past few decades, many studies have shown that it involves not only hormone levels and the hematologic, respiratory, and cardiovascular systems but also the nervous system and psychology [2,813].

Many studies of high-altitude de-acclimatization have been reported. However, the symptoms experienced by subjects have received little attention. Individuals subjected to short-term exposure to high altitudes, on the scale of a few days, experience symptoms so light that they cannot always be observed. However, some climbers complain of headaches and fidgetiness when they descend to sea level from high altitudes. Zubieta-Calleja showed that visitors from high altitudes suffered from excessive somnolence, lower limb edema, diminished reflexes, and inadequate fine motor coordination when they descend to sea level [14]. Cui et al. demonstrated that $70.76 \%$ of individuals, who live at high altitudes for 10-30 years, present a series of clinical symptoms including fatigue, headache, and sleepiness [15]. Our previous study showed that $84.36 \%$ of individuals who had lived in Tibet for 10-20 years presented a series of clinical symptoms including fatigue, sleepiness, insomnia, unresponsiveness, memory loss, fidgetiness, headache, throat pain or discomfort, coughing, expectoration, chest tightness, flustering, increased appetite, decreased appetite, constipation, diarrhea, abdominal distention, abdominal pain, lumbago, arthralgia, and some abnormal physiological parameters of the cardiovascular, hematological, and respiratory systems upon returning to lower altitudes [16]. These symptoms were not observed in healthy individuals who had not visited high altitudes. 
Other studies have shown that several of these symptoms can last many years in some severe cases, and 1\%o of subjects experienced such severe symptoms that they had to return to high altitudes [17]. We refer to all of the above pathological features as a highaltitude de-acclimatization syndrome [18,19].

Previous studies of high-altitude de-acclimatization syndrome have focused on long-term ( $>1$ year) exposure to high altitudes. We have proposed that existing diagnostic and scoring criteria for high-altitude de-acclimatization are appropriate for populations subjected to long-term exposures to high altitudes [16,20]. The incidences of symptoms, duration of symptoms, hematologic function, cardiovascular function, and levels of reactive oxygen species (ROS) associated with high-altitude de-acclimatization symptoms have been reported [16,21-23].

Following the expansion of railway and air travel in Qinghai and Tibet, many people have come to live in high-altitude areas for relatively short periods of time $(\leq 1$ year) for such purposes as earthquake relief, commerce, education, and work. The incidence of de-acclimatization symptoms upon the return to lower altitudes has increased by as much as 100\% [23]. Accurate understanding and treatment of this condition is hindered by diagnostic and scoring criteria designed for use with individuals subjected to longterm exposure to high altitudes, rather than fixed time exposure $(\leq 1$ year, $>8$ weeks). For this reason, we analyzed epidemiological study data from subjects who had returned to Chongqing, Kunming, and other areas after spending less than 1 year in high-altitude areas. We recommend modifications to the diagnostic and scoring criteria used with subjects exposed to high altitudes for fixed periods of time.

This report provides symptom scores and diagnostic criteria for fixed time ( $\leq 1$ year, $>8$ weeks) de-acclimatization syndrome and demonstrates the symptoms generated are connected with the changes of red blood cell mass (RBC), hemoglobin $(\mathrm{Hb})$, hematocrit (Hct), arterial partial pressure of oxygen $(\mathrm{PaO} 2)$, partial pressure of carbon dioxide $(\mathrm{PaCO} 2)$, oxygen saturation $(\mathrm{SaO} 2)$, creatine kinase $(\mathrm{CK})$, creatine kinase-MB (CK-MB), and lactate dehydrogenase $(\mathrm{LDH})$, which have specific relationships with reoxygenation after hypoxia. The symptom scores were associated with differences in altitude, symptom characteristics, hematological cell levels, blood gas, and myocardial enzyme levels. They slowly returned to baseline, as indicated by measurements taken on the 3rd, 50th, and 100th days after the subjects' return to either Chongqing or Kunming. However, the recovery of fixed time de-acclimatization symptoms required a long time, more than 100 days.

\section{Methods}

\section{Subjects and general protocols}

Sixty-seven healthy men (33.42 \pm 8.12 years old) from Chongqing $(180 \mathrm{~m})$ and 70 healthy men $(32.9 \pm 7.32$ years old) from Kunming $(1800 \mathrm{~m})$ served as the high-altitude de-acclimatization syndrome group (HDAS group). Ninety-two healthy men (31.33 \pm 7.47 years old) from Chongqing and 87 healthy men from Kunming (30.33 \pm 11.59 years old) who had not been exposed to high altitudes served as controls. The two groups were not statistically different in age and place of permanent residence $(\mathrm{P}>0.05)$.

Subjects who came from Chongqing or Kunming maintained the same activity levels in Lhasa as in Chongqing or Kunming. (1) Altitude. Individuals arrived at the same altitude $(3650 \mathrm{~m})$ and worked at two spring water factories, respectively. (2) Working conditions. They worked in workshops. These were similar to workshops in Chongqing and Kunming with respect to work environment and temperature. (3) Work intensity. The subjects maintained the same level of intensity at all three locations. (4) Work day. The work day lasted for 7 hours per day, 5 days per week. Subjects kept the same schedule at high and low altitude. (5) Dietary pattern. The subjects kept the similar dietary pattern at all three locations. Subjects were required to eat three meals every day in their factory cafeteria. (6) Work season. All subjects worked in Lhasa from March to October or November. The weather during this period, summer and autumn, is suitable for this type of work, because oxygen content in air is higher $(10 \%)$ than in winter $(6 \%)$.

Physicians were trained by the trial manager to evaluate symptoms of subjects, and experienced technicians were trained standard procedures for collecting arterial blood before trail carried out. Subjects had been diagnosed with high-altitude deacclimatization syndrome according to relevant diagnostic and scoring criteria. Symptom scores were assessed as the described below.

Subjects had worked in Lhasa $(3650 \mathrm{~m})$ about 6 months and then returned to Chongqing or Kunming by airplane. After they came back, all subjects were evaluated for high-altitude deacclimatization syndrome on the $3^{\text {rd }}, 50^{\text {th }}$, and $100^{\text {th }}$ days. Symptom scores, routine blood and blood gas tests, and myocardial zymograms assay were used for observation their syndrome. All Subjects provided written informed consent. This study was approved by the medical ethical committee of the Second Affiliated Hospital, Third Military Medical University.

\section{Diagnostic and scoring criteria for fixed period high- altitude de-acclimatization syndrome}

The diagnostic and scoring criteria for high altitude deacclimatization syndrome are based on epidemiological study data. They are modified versions of our previous scoring criteria [16].

1. Essential diagnostic criteria for high altitude deacclimatization syndrome. (1) Adult $\leq 60$ years old. (2) Recent return to lower altitude from a higher altitude. (3) Three or more of the following symptoms: fatigue, sleepiness, insomnia, unresponsiveness, memory loss, fidgety, headache, throat pain or discomfort, coughing, expectoration, chest tightness, flustering, increased appetite, decreased appetite, expectoration, diarrhea, abdominal distention, abdominal pain, lumbago, or arthralgia. (4) No significant relief of symptoms after 3 days of simple medication administered after the return to lower altitudes.

2. Auxiliary diagnostic criteria for high altitude deacclimatization syndrome. (1) Blood routine: $\mathrm{RBC}, \mathrm{Hb}$, and Hct levels high above baseline. (2) Myocardial enzymes: CK-MB and LDH levels above those of individual's native to low altitudes. (3) Urine: Microalbuminuria above that of individual's native to low altitudes. (4) Heart function: Pulmonary arterial pressure slightly higher than that of individuals native to high altitudes accompanied by left or right ventricular systolic and diastolic dysfunction. Raised Tei index coupled with low values of left ventricular ejection fraction (LVEF), right ventricular ejection fraction (RVEF), left ventricular fractional shortening (LVFS), and right ventricular fractional shortening (RVFS). (5) Brain function: Dysfunction of immediate short-term memory. (6) Hepatic function: Total bilirubin, ALT, and AST levels higher than those of individual's native to low altitudes.

Diagnosis of high altitude de-acclimatization included essential conditions and one Auxiliary condition.

3. Exclusion criteria. (1) Symptoms directly attributable to primary diseases affecting the cardiovascular, respiratory, nervous, urinary, and hematological systems. (2) Cancer or leukemia. (3) 
Table 1. Classification and scoring criteria of the symptoms of high-altitude de-acclimatization syndrome.

\begin{tabular}{|c|c|c|}
\hline Classification & Judgment standards & Scoring standards \\
\hline \pm & Mild symptoms with no impact on daily life & 0 \\
\hline+ & Mild symptoms with slight impact on daily life, ameliorated after drug regimen & 1 \\
\hline++ & Severe symptoms affect daily life, somewhat alleviated after drug regimen & 2 \\
\hline +H & Severe symptoms affect daily life, no significant relief after drug regimen & 3 \\
\hline
\end{tabular}

Any history of highland heart disease or high-altitude polycythemia. (4) Recent history of flu, upper respiratory tract infection, infectious diarrhea, or similar symptoms.

4. Classification and scoring criteria of the symptoms of high-altitude de- acclimatization syndrome (Tables 1 and 2).

5. Symptom scores. Symptom scores were evaluated according to the scoring criteria for fixed-duration high-altitude de-acclimatization syndrome.

\section{Biological measurements}

1. Blood gas assay. Technician is to follow physician order for collecting the sample of arterial blood gas. If sample collection was failed, all of blood gas data of this subject was been eliminated.

Blood gas collecting procedures: The skin over the puncture site in radial artery is cleaned with $70 \%$ isopropyl alcohol. Insert the needle through the skin into the artery taking care not to puncture the posterior wall of the artery. Withdraw the needle when an adequate sample has been obtained. Immediately place dry gauze over the puncture site and apply pressure. Maintain pressure over puncture site for a minimum of 5 minutes. All samples were analyzed within $30 \mathrm{~min}$ of arterial puncture using a blood gas analyzer (Lexington, MA, IL-1620, US).

2. Collection and analysis of blood samples. Morning fasting venous blood $(1 \mathrm{ml})$ was collected (with EDTA-K2), and samples were assayed within 2 hours using an hematology analyzer (Sysmex XE-2100, Japan) at the Forty-eighth Hospital in Lhasa, Xinqiao Hospital in Chongqing, and the 478th Hospital in Kunming. The operation was performed in strict according with the standard SOP. All equipment was used in accordance with the manufacturers' protocols. The same types of equipment were used at all three sites and they showed statistically similar levels of efficiency $(\mathrm{P}<0.01)$.

3. Measurement of myocardial enzymes. Morning fasting venous blood $(3 \mathrm{ml})$ was collected, centrifuged at $4000 \mathrm{r} / \mathrm{min}$ for $10 \mathrm{~min}$ to separate serum, and stored at $-80^{\circ} \mathrm{C}$ before assay. The concentrations of $\mathrm{CK}, \mathrm{CK}-\mathrm{MB}$, and $\mathrm{LDH}$ were measured at Xinqiao Hospital on a fully automated biochemistry analyzer (Olympus Au2700, Japan).
4. Rates of change. Altitude de-acclimatization symptom scores recorded on the 3rd day after the return to plains areas served as baseline. Rate of change rate $1=($ score on 50 th dayscore on 3rd day)/score on 3rd day $\times 100 \%$; rate of change $2=($ score on 100 th day-score on $3 \mathrm{rd}$ day $) /$ score on $3 \mathrm{rd}$ day $\times 100 \%$.

RBC levels recorded at high altitudes served as a baseline value. Rate of change $1=$ (value on 3rd day-value at high altitudes)/value at high altitudes $\times 100 \%$; rate of change $2=($ value on 50 th dayvalue at high altitudes)/value at high altitudes $\times 100 \%$; rate of change $3=($ value on 100th day-value at high altitudes)/value at high altitudes $\times 100 \%$. The rate of change rate of CK, CK-MB, and $\mathrm{LDH}$ was same the same as the rate of change in RBC count.

\section{Statistical analysis}

SPSS 15.0 for windows was used for statistical analysis. All data are presented as the arithmetic mean values (SD). Percent of symptoms dates ware compared by $\chi 2$ test. Symptoms score, RBC, Hb, Hct, MCV, MCH, MCHC, WBC, Neu\%, CK, CK$\mathrm{MB}$ and $\mathrm{LDH}$ obtained in the various sessions were compared by repeated- measure analysis of variance (ANOVA). The unpaired ttest was used as a post-hoc test to evaluate the significance of differences between Chongqing group and Kunming group. The level of significance was taken at $\mathrm{P}<0.05$.

\section{Results}

\section{Symptom scores}

The altitude de-acclimatization syndrome symptom scores of the Chongqing and Kunming groups were evaluated by physicians on the $3^{\text {rd }}, 50^{\text {th }}$, and $100^{\text {th }}$ days upon returned to low-altitude areas after 6 months of exposure to high altitudes, as shown in Figure 1.

In the Chongqing group, the altitude de-acclimatization syndrome symptom scores of subjects were $13.38 \pm 3.31$ on the $3^{\text {rd }}$ day, $5.71 \pm 2.04$ on the $50^{\text {th }}$ day, and $3.05 \pm 1.51$ on the $100^{\text {th }}$ day. Scores were significantly higher on the $3^{\text {rd }}$ day than on the $50^{\text {th }}$ or $100^{\text {th }}$ (both $\left.P<0.05\right)$. Scores were significantly higher on the $50^{\text {th }}$ day than on the $100^{\text {th }}(P<0.05)$.

Table 2. Grading of high-altitude altitude de-acclimatization syndrome.

\begin{tabular}{ll}
\hline Classification & Diagnostic criteria \\
\hline Almost no reaction $( \pm)$ & Suspected symptoms $( \pm$ ) or $0-5$ total points \\
Mild reaction $(+)$ & Slight symptoms $(+)$ or $6-15$ total points \\
Moderate reaction $(++)$ & More serious symptoms $(++)$ or $16-25$ total points \\
Severe reaction $(+++)$ & Very serious symptoms $(+++)$ or 26 or more total points \\
\hline doi:10.1371/journal.pone.0062072.t002 &
\end{tabular}




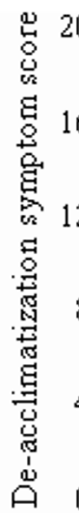

Time (day)

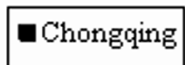

$\square$ Kumming

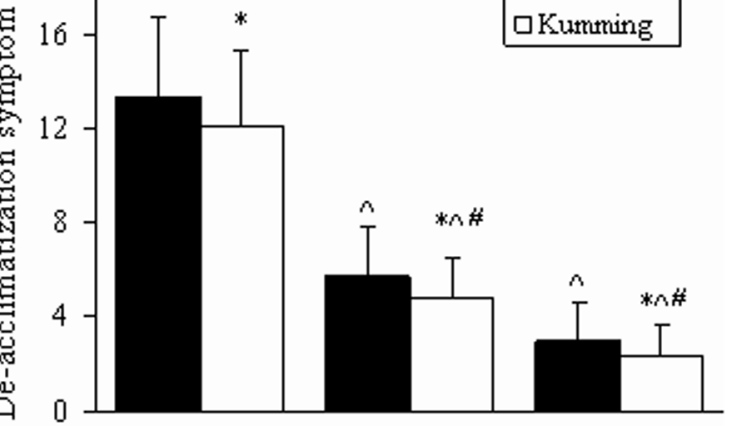

Figure 1. Symptom scores. Data are presented as mean $\pm S D$. ${ }^{*} P<0.05$, relative to the Chongqing group. ${ }^{\wedge} P<0.05$, relative to the $3^{\text {rd }}$ day, ${ }^{\#} P<0.05$, relative to the $50^{\text {th }}$ day.

doi:10.1371/journal.pone.0062072.g001

In the Kunming group, altitude de-acclimatization syndrome symptom scores were $12.12 \pm 3.16$ on the $3^{\text {rd }}$ day, $4.75 \pm 1.73$ on the $50^{\text {th }}$ day, and $2.35 \pm 1.33$ on the $100^{\text {th }}$ day. Scores were significantly higher on the $3^{\text {rd }}$ day than on the $50^{\text {th }}$ day or $100^{\text {th }}$ day (both $P<0.05)$. Scores were significantly higher on the $50^{\text {th }}$ day than on the $100^{\text {th }}(P<0.05)$.

The Chongqing and Kunming groups were compared on the $3^{\text {rd }}, 50^{\text {th }}$, and $100^{\text {th }}$ days after return to low-altitude areas. Altitude de-acclimatization syndrome symptom scores were significantly higher in the Chongqing group at all three points in time (all $P<0.05)$.

These results indicate that the symptoms of altitude deacclimatization syndrome should be improved over time. The symptoms were more serious in the Chongqing group than in the Kunming group.

Rates of change 1 and 2 showed no significant differences between the Chongqing group and Kunming group (both $P>0.05$ ) (Figure 2).

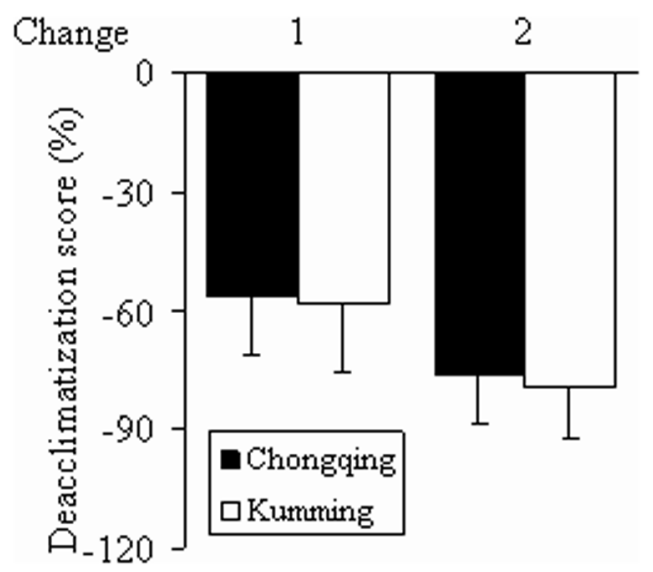

Figure 2. Rates of change in symptom scores. Data are presented as mean \pm SD. Symptom scores recorded on the $3^{\text {rd }}$ day after return to low-altitude areas served as baseline values. Rate of change $1=$ (score on $50^{\text {th }}$ day-score on $3^{\text {rd }}$ day)/score on $3^{\text {rd }}$ day $\times 100 \%$; rate of change $2=\left(\right.$ score on $100^{\text {th }}$ day-score on $3^{\text {rd }}$ day $) /$ score on $3^{\text {rd }}$ day $\times 100 \%$. Rates of change 1 and 2 showed no significant difference between the Chongqing and Kunming groups $(P>0.05)$.

doi:10.1371/journal.pone.0062072.g002

\section{Incidence}

The incidence of symptoms of high altitude de-acclimatization syndrome in both Chongqing and Kunming subjects are illustrated in detail in Table 3 .

The most common symptoms were fatigue, dizziness and coughing, reported in $73.13 \%, 73.13 \%$, and $73.13 \%$ of 67 subjects on the $3^{\text {rd }}$ day after the return to Chongqing. These symptoms were reported in $50.00 \%, 50.00 \%$, and $52.85 \%$ of 70 subjects on the $3^{\text {rd }}$ day after the return to Kunming.

On the $3^{\text {rd }}$ day, the incidence of all symptoms except fatigue, expectoration, increased appetite, constipation, diarrhea, and abdominal pain was higher among subjects who returned to Chongqing than among those who returned to Kunming. The incidence of all symptoms decreased significantly over time. On the $100^{\text {th }}$ day after the return, unresponsiveness, headache, coughing, and flustering were only slightly higher in the Chongqing group than in the Kunming group.

These data suggest that the greater the descent from high altitude to low, the greater the incidence of symptoms of altitude de-acclimatization syndrome.

Changes in $\mathrm{pH}, \mathrm{PaO}_{2}, \mathrm{PaCO}_{2}$, and $\mathrm{SaO}_{2}$ after the return

In the low altitude, the samples were collected successfully. In the high altitude, the samples collection rate is $94.7 \%$ (36/38).

No significant differences in $\mathrm{pH}$ were observed among values recorded at baseline, high altitudes, and on the $3^{\text {rd }}$ day after the return to Chongqing or Kunming. $\mathrm{PaO}_{2}$ and $\mathrm{SaO}_{2}$ values were higher on the $3^{\text {rd }}$ day than at high altitudes. Values recorded at high altitudes showed no difference from baseline values. The levels of $\mathrm{PaCO}_{2}$ were higher on the $3^{\text {rd }}$ day after the return to Chongqing than at high altitudes. No other differences were observed within these Kunming groups. Compared with control group at high altitudes 6 months time point, $\mathrm{PaO}_{2}, \mathrm{PaCO}_{2}$ and $\mathrm{SaO}_{2}$ were significant elevated in HDAS group. (Tables 4 and 5).

\section{Changes in hematologic parameters after the return}

Changes in hematologic parameters of subjects on the $3^{\text {rd }}, 50^{\text {th }}$, and $100^{\text {th }}$ days after the return to Chongqing and Kunming after 6 months of exposure to high altitudes are illustrated in detail in Tables 6 and 7 .

RBC counts were lower on the $3^{\text {rd }}$ day after the return than at high altitudes but still higher than baseline values (both $P<0.05$ ). They were lower on the $50^{\text {th }}$ and $100^{\text {th }}$ days than on the $3^{\text {rd }}$ day (all $P<0.05$ ). Values had returned to baseline by the $50^{\text {th }}$ day in the Chongqing group and by the $100^{\text {th }}$ day in the Kunming group $(P>0.05)$.

$\mathrm{Hb}$ levels were lower on the $3^{\text {rd }}$ day after the return than those recorded at high altitudes $(P<0.05)$. The levels recorded on the $50^{\text {th }}$ and $100^{\text {th }}$ days were lower than those recorded on the $3^{\text {rd }}$ day (both $P<0.05$ ). Hct levels were significantly lower on the $3^{\text {rd }}$ day after the return than at high altitudes. The levels of $\mathrm{Hb}$ and Hct had returned to near-baseline levels by the $100^{\text {th }}$ day $(P>0.05)$.

Compared with control group, RBC counts, $\mathrm{Hb}$ and Hct were higher on the High altitude 6 months and $3^{\text {rd }}$ day after the return in HDAS group $(P<0.05)$. The levels of $\mathrm{Hb}$ were found to be significantly higher on the $50^{\text {th }}$ days than control group in Chongqing $(P<0.05)$.

However, on the $3^{\text {rd }}$ day after the return, WBC counts were significantly higher than at baseline or at high altitudes (both $P<0.05)$. WBC counts were significantly lower on the $50^{\text {th }}$ and $100^{\text {th }}$ days than on the $3^{\text {rd }}(P<0.05)$. No statistically significant differences were observed between the $50^{\text {th }}$ and $100^{\text {th }}$ days $(P>0.05)$. The relative number of neutrophils showed similar tendencies. 
Table 3. Incidence of symptoms of subjects after returning to Chongqing or Kunming after visiting high altitudes.

\begin{tabular}{|c|c|c|c|c|c|c|}
\hline \multirow[b]{2}{*}{ Symptoms } & \multicolumn{3}{|c|}{ Chongqing group $(n=67)$} & \multicolumn{3}{|c|}{ Kunming group $(n=70)$} \\
\hline & $3^{\text {rd }}$ day & $50^{\text {th }}$ day & $100^{\text {th }}$ day & $3^{\text {rd }}$ day & $50^{\text {th }}$ day & $100^{\text {th }}$ day \\
\hline Fatigue & 49 (73.13\%) & $27(40.29 \%)^{\#}$ & $8(11.94 \%)^{\&}$ & $35(50.00 \%)$ & $19(27.14 \%)^{\#}$ & $6(8.57 \%)^{\&}$ \\
\hline Sleepiness & $48(71.64 \%)^{*}$ & $22(32.83 \%)^{\#}$ & $9(13.43 \%)^{\&}$ & 33 (47.14\%) & $20(28.57 \%)^{\#}$ & 11 (15.71\%) \\
\hline Insomnia & $29(43.28 \%)^{*}$ & $23(34.32 \%)^{*}$ & $9(13.43 \%)^{\&}$ & 19 (27.14\%) & $13(18.57 \%)$ & $8(11.42 \%)$ \\
\hline Unresponsiveness & $31(46.26 \%)^{*}$ & $10(14.92 \%)^{* \#}$ & $5(7.46 \%)$ & $11(15.71 \%)$ & $8(11.42 \%)$ & $3(4.28 \%)$ \\
\hline Memory loss & $31(46.26 \%)^{*}$ & 20 (29.85\%) & $10(14.92 \%)^{\&}$ & $22(31.42 \%)$ & $18(25.71 \%)$ & $9(12.85 \%)^{8}$ \\
\hline Agitation & $30(44.77 \%)^{*}$ & 24 (35.82\%) & $12(17.91 \%)^{\&}$ & $20(28.57 \%)$ & $12(17.14 \%)$ & $7(10.00 \%)$ \\
\hline Headache & $36(53.73 \%)^{*}$ & $27(40.29 \%)^{*}$ & $14(20.89 \%)^{* \&}$ & $20(28.57 \%)$ & $12(17.14 \%)$ & $6(8.57 \%)$ \\
\hline Dizziness & $49(73.13 \%)^{*}$ & $27(40.29 \%)^{\#}$ & $23(17.91 \%)$ & $35(50.00 \%)$ & $26(37.14 \%)$ & $16(22.85 \%)$ \\
\hline Throat pain or discomfort & $28(41.79 \%)^{*}$ & $14(20.89 \%)^{\#}$ & 7 (10.44\%) & 15 (21.42\%) & $8(11.42 \%)$ & $4(5.71 \%)^{\&}$ \\
\hline Coughing & $49(73.13 \%)^{*}$ & $30(44.76 \%)^{* \#}$ & $21(31.34 \%)^{*}$ & 37 (52.85\%) & $18(14.28 \%)^{\#}$ & $6(8.57 \%)$ \\
\hline Expectoration & $31(46.26 \%)$ & $16(23.88 \%)^{\#}$ & $8(26.86 \%)$ & $35(50.00 \%)$ & $8(11.42 \%)^{\#}$ & $5(7.14 \%)$ \\
\hline Chest tightness & $37(55.22 \%)^{*}$ & $23(34.32 \%)^{*} \#$ & $10(14.92 \%)^{8}$ & $17(24.28 \%)$ & $10(14.28 \%)$ & $6(8.57 \%)$ \\
\hline Flustering & $41(61.19 \%)^{*}$ & $25(37.31 \%)^{* \#}$ & $18(26.86 \%)^{*}$ & $25(35.71 \%)$ & $13(18.57 \%)^{\#}$ & $5(7.14 \%)^{\&}$ \\
\hline Increased appetite & $31(46.26 \%)$ & $11(16.41 \%)^{\#}$ & $3(4.47 \%)^{8}$ & $22(31.42 \%)$ & $8(11.42 \%)^{\#}$ & $1(1.42 \%)^{\&}$ \\
\hline Decreased appetite & $27(40.29 \%)^{*}$ & $17(25.37 \%)^{* \#}$ & $5(7.46 \%)^{8}$ & $17(24.28 \%)$ & $10(14.28 \%)$ & $4(5.71 \%)$ \\
\hline Constipation & $22(32.83 \%)$ & $8(11.94 \%)^{\#}$ & $1(1.49 \%)^{\&}$ & 19 (27.14\%) & $6(8.57 \%)$ & $0(0.00 \%)^{\&}$ \\
\hline Diarrhea & $18(26.86 \%)$ & $8(11.94 \%)^{\#}$ & $1(1.49 \%)^{\&}$ & $13(18.57 \%)$ & $6(8.57 \%)$ & $1(1.42 \%)$ \\
\hline Abdominal distention & $44(66.67 \%)^{*}$ & $28(41.79 \%)$ & $20(29.85 \%)^{8}$ & $32(45.71 \%)$ & $20(28.57 \%)^{\#}$ & $6(8.57 \%)^{8}$ \\
\hline Abdominal pain & $40(59.70 \%)$ & $29(43.28 \%)^{\#}$ & $13(19.40 \%)$ & 31 (44.28\%) & $21(30.00 \%)$ & $9(12.85 \%)^{8}$ \\
\hline Lumbago & $29(43.28 \%)^{*}$ & $14(20.89 \%)^{* \#}$ & $10(14.92 \%)$ & $10(14.28 \%)$ & $4(5.71 \%)$ & $4(5.71 \%)$ \\
\hline Arthralgia & $39(58.20 \%)^{*}$ & $15(22.38 \%)^{*} \#$ & 11 (16.41\%) & $18(25.71 \%)$ & 7 (10.00\%) & $5(7.14 \%)$ \\
\hline
\end{tabular}

Data are given as the number (\%). ${ }^{*} P<0.05$ relative to the Kunming group, ${ }^{\#} P<0.05$, relative to $3^{\text {rd }}$ day values, ${ }^{\&} P<0.05$, relative to $50^{\text {th }}$ day values.

doi:10.1371/journal.pone.0062072.t003

Table 4. $\mathrm{pH}, \mathrm{PaO} 2, \mathrm{PaCO} 2$, and $\mathrm{SaO} 2$ of subjects after returning to Chongqing.

\begin{tabular}{lll}
\hline & & \\
\hline & HDAS group & Control group \\
\hline Baseline & $\mathbf{n}=\mathbf{2 3}$ & $\mathbf{n}=\mathbf{2 5}$ \\
$\mathrm{pH}$ & $7.39 \pm 0.01$ & $7.39 \pm 0.03$ \\
$\mathrm{PaO}_{2}(\mathrm{hPa})$ & $126.97 \pm 5.59$ & $128.37 \pm 5.26$ \\
$\mathrm{PaCO}_{2}(\mathrm{hPa})$ & $49.38 \pm 2.90$ & $49.46 \pm 2.52$ \\
$\mathrm{SaO}_{2}(\%)$ & $97.36 \pm 0.53$ & $98.36 \pm 0.46$ \\
$\mathbf{H i g h}$ altitudes $\mathbf{6}$ & $\mathbf{n}=\mathbf{1 6}$ & $\mathbf{n}=\mathbf{2 4}$ \\
$\mathbf{m o n t h s}$ & & $7.41 \pm 0.03$ \\
$\mathrm{pH}$ & $7.45 \pm 0.06$ & $129.12 \pm 4.22$ \\
$\mathrm{PaO}_{2}(\mathrm{hPa})$ & $81.58 \pm 4.33^{*} \triangle$ & $51.28 \pm 3.27$ \\
$\mathrm{PaCO}_{2}(\mathrm{hPa})$ & $35.00 \pm 4.41^{*} \triangle$ & $97.85 \pm 0.89$ \\
$\mathrm{SaO}_{2}(\%)$ & $87.32 \pm 1.45^{*}$ & $\mathbf{n}=\mathbf{2 2}$ \\
$\mathbf{3}^{\text {rd }}$ day & $\mathbf{n}=\mathbf{1 3}$ & $7.38 \pm 0.04$ \\
$\mathrm{pH}^{*}$ & $7.40 \pm 0.03$ & $128.78 \pm 4.38$ \\
$\mathrm{PaO}_{2}(\mathrm{hPa})$ & $125.84 \pm 3.27^{\&}$ & $51.79 \pm 3.83$ \\
$\mathrm{PaCO}_{2}(\mathrm{hPa})$ & $46.85 \pm 1.94^{\&}$ & $97.45 \pm 0.63$ \\
$\mathrm{SaO}_{2}(\%)$ & $96.78 \pm 0.85^{\&}$ &
\end{tabular}

Data are given as the mean \pm SD. ${ }^{*} P<0.05$, relative to baseline, ${ }^{8} P<0.05$, relative to high altitude values recorded at 6 months, $\triangle P<0.05$, relative to the control group

doi:10.1371/journal.pone.0062072.t004
Table 5. $\mathrm{pH}, \mathrm{PaO} 2, \mathrm{PaCO} 2$, and $\mathrm{SaO} 2$ of subjects after returning to Kunming.

\begin{tabular}{lll}
\hline & & \\
\hline & HDAS group & Control group \\
\hline Baseline & $\mathbf{n}=\mathbf{3 1}$ & $\mathbf{n}=\mathbf{3 3}$ \\
$\mathrm{pH}$ & $7.40 \pm 0.02$ & $7.42 \pm 0.04$ \\
$\mathrm{PaO}_{2}(\mathrm{hPa})$ & $119.76 \pm 6.49$ & $119.49 \pm 5.26$ \\
$\mathrm{PaCO}_{2}(\mathrm{hPa})$ & $45.39 \pm 2.75$ & $46.51 \pm 3.52$ \\
$\mathrm{SaO}_{2}(\%)$ & $95.36 \pm 0.83$ & $96.11 \pm 0.59$ \\
$\mathbf{H i g h}$ altitudes $\mathbf{6}$ & $\mathbf{n = 2 0}$ & $\mathbf{n}=\mathbf{2 7}$ \\
$\mathbf{m o n t h s}$ & & \\
$\mathrm{pH}$ & $7.43 \pm 0.09$ & $7.39 \pm 0.05$ \\
$\mathrm{PaO}_{2}(\mathrm{hPa})$ & $88.87 \pm 4.33^{*} \triangle$ & $121.12 \pm 6.22$ \\
$\mathrm{PaCO}_{2}(\mathrm{hPa})$ & $37.45 \pm 5.47^{\triangle}$ & $47.32 \pm 2.27$ \\
$\mathrm{SaO}_{2}(\%)$ & $89.32 \pm 1.32^{*} \triangle$ & $94.85 \pm 1.23$ \\
$\mathbf{3}^{\text {rd }}$ day & $\mathbf{n}=\mathbf{1 6}$ & $\mathbf{n}=\mathbf{2 2}$ \\
$\mathrm{pH}^{*}$ & $7.41 \pm 0.07$ & $7.40 \pm 0.06$ \\
$\mathrm{PaO}_{2}(\mathrm{hPa})$ & $120.10 \pm 7.48^{\&}$ & $12.35 \pm 4.38$ \\
$\mathrm{PaCO}_{2}(\mathrm{hPa})$ & $42.73 \pm 4.13$ & $44.78 \pm 3.98$ \\
$\mathrm{SaO}_{2}(\%)$ & $94.42 \pm 1.02^{\&}$ & $95.25 \pm 0.98$ \\
\hline
\end{tabular}

Data are given as the mean \pm SD. ${ }^{*} P<0.05$, relative to baseline, ${ }^{8} P<0.05$, relative to high altitude values, $\triangle P<0.05$, relative to the control group doi:10.1371/journal.pone.0062072.t005 
Table 6. Whole blood test results of subjects after returning to Chongqing.

\begin{tabular}{|c|c|c|c|c|c|c|}
\hline Group & Parameter & Baseline & $\begin{array}{l}\text { High altitudes } 6 \\
\text { months }\end{array}$ & $3^{\text {rd }}$ day & $50^{\text {th }}$ day & $100^{\text {th }}$ day \\
\hline \multirow{8}{*}{$\begin{array}{l}\text { HDAS group } \\
(n=67) .\end{array}$} & $\mathrm{RBC}\left(\times 10^{12}\right)$ & $4.90 \pm 0.23$ & $5.89 \pm 0.57^{*} \triangle$ & $5.43 \pm 0.62^{* \& \triangle}$ & $4.97 \pm 0.38^{\& \#}$ & $4.91 \pm 0.30^{8 \#}$ \\
\hline & $\mathrm{Hb}(\mathrm{g} / \mathrm{L})$ & $143.70 \pm 11.14$ & $177.94 \pm 13.02^{*} \triangle$ & $168.36 \pm 9.32^{*} \& \triangle$ & $156.85 \pm 8.87^{\& \# \Delta}$ & $146.73 \pm 8.45^{\& \#}$ \\
\hline & Hct (\%) & $40.19 \pm 2.48$ & $55.69 \pm 4.03^{*} \triangle$ & $47.11 \pm 3.02^{*} \& \Delta$ & $41.46 \pm 2.71^{\&}$ & $42.79 \pm 2.54^{\&}$ \\
\hline & $\mathrm{MCV}(\mathrm{fL})$ & $81.96 \pm 3.58$ & $93.29 \pm 6.52^{*} \triangle$ & $91.72 \pm 5.72^{*} \triangle$ & $90.64 \pm 5.51^{*}$ & $85.27 \pm 4.26^{8 \#}$ \\
\hline & $\mathrm{MCH}(\mathrm{pg})$ & $31.35 \pm 1.70$ & $30.36 \pm 2.51$ & $32.68 \pm 2.69^{*} \& \Delta$ & $31.23 \pm 2.09^{\& \#}$ & $32.02 \pm 1.21^{\& \#}$ \\
\hline & RDW (\%) & $13.96 \pm 0.46$ & $13.97 \pm 0.92$ & $13.61 \pm 0.98^{\&}$ & $11.76 \pm 0.77^{*} \& \# \Delta$ & $13.62 \pm 0.4 \hat{8}^{\triangle}$ \\
\hline & WBC $\left(\times 10^{9}\right)$ & $5.84 \pm 0.96$ & $6.07 \pm 1.64$ & $7.47 \pm 1.63^{* \& \triangle}$ & $5.90 \pm 1.85^{\#}$ & $5.61 \pm 1.22^{\#}$ \\
\hline & Neu (\%) & $50.99 \pm 6.86$ & $53.71 \pm 8.67$ & $63.09 \pm 6.41^{* \& \Delta}$ & $54.24 \pm 8.35^{\#}$ & $54.49 \pm 7.17^{\#}$ \\
\hline \multirow{8}{*}{$\begin{array}{l}\text { Control group } \\
(n=92)\end{array}$} & $\mathrm{RBC}\left(\times 10^{12}\right)$ & $4.85 \pm 0.37$ & $4.97 \pm 0.29$ & $4.79 \pm 0.34$ & $4.80 \pm 0.16$ & $4.90 \pm 0.18$ \\
\hline & $\mathrm{Hb}(\mathrm{g} / \mathrm{L})$ & $143.53 \pm 6.92$ & $149.26 \pm 7.15$ & $147.40 \pm 6.44$ & $147.33 \pm 6.12$ & $145.26 \pm 6.61$ \\
\hline & Hct (\%) & $41.74 \pm 2.92$ & $40.97 \pm 3.38$ & $41.97 \pm 2.93$ & $41.52 \pm 3.34$ & $40.70 \pm 3.06$ \\
\hline & $\mathrm{MCV}(\mathrm{fL})$ & $83.96 \pm 3.17$ & $84.74 \pm 4.33$ & $85.16 \pm 3.73$ & $85.62 \pm 3.47$ & $84.70 \pm 3.05$ \\
\hline & $\mathrm{MCH}(\mathrm{pg})$ & $30.25 \pm 1.99$ & $29.30 \pm 1.66$ & $29.98 \pm 1.53$ & $30.08 \pm 1.44$ & $30.19 \pm 1.30$ \\
\hline & RDW (\%) & $14.09 \pm 0.39$ & $13.95 \pm 0.60$ & $13.85 \pm 0.71$ & $14.08 \pm 0.77$ & $13.99 \pm 0.68$ \\
\hline & WBC $\left(\times 10^{9}\right)$ & $5.98 \pm 0.98$ & $5.75 \pm 0.86$ & $5.81 \pm 0.73$ & $5.90 \pm 0.91$ & $5.87 \pm 0.79$ \\
\hline & Neu (\%) & $53.58 \pm 6.18$ & $55.72 \pm 3.24$ & $55.46 \pm 3.34$ & $56.77 \pm 3.31$ & $56.48 \pm 3.52$ \\
\hline
\end{tabular}

Data are given as the mean $\pm \mathrm{SD}$. RBC = red blood cell, $\mathrm{Hb}=$ hemoglobin, $\mathrm{Hct}=$ hematocrit, $\mathrm{MCV}=$ mean corpuscular volume, $\mathrm{MCH}=$ mean corpuscular hemoglobin, $\mathrm{MCHC}=$ mean corpuscular hemoglobin concentration, RDW = red blood cell volume distribution width, WBC = white blood cell, Neu = neutrophil. ${ }^{*} P<0.05$, relative to baseline, ${ }^{\&} P<0.05$, relative to high altitude values, ${ }^{\#} P<0.05$, relative to $3^{\text {rd }}$ day values, ${ }^{\wedge} P<0.05$, relative to $50^{\text {th }}$ day values, ${ }^{\triangle} P<0.05$, relative to the control group.

doi:10.1371/journal.pone.0062072.t006

Table 7. Whole blood test results of subjects after returning to Kunming.

\begin{tabular}{|c|c|c|c|c|c|c|}
\hline Group & Parameter & Baseline & $\begin{array}{l}\text { High altitudes } 6 \\
\text { months }\end{array}$ & $3^{\text {rd }}$ day & $50^{\text {th }}$ day & $100^{\text {th }}$ day \\
\hline \multirow{8}{*}{$\begin{array}{l}\text { HDAS group } \\
(n=70)\end{array}$} & $\mathrm{RBC}\left(\times 10^{12}\right)$ & $5.15 \pm 0.43$ & $5.69 \pm 0.32^{*} \triangle$ & $5.54 \pm 0.50^{*} \& \triangle$ & $5.23 \pm 0.31^{\& \#}$ & $5.08 \pm 0.38^{8 \#}$ \\
\hline & $\mathrm{Hb}(\mathrm{g} / \mathrm{L})$ & $151.65 \pm 9.31$ & $180.50 \pm 15.90^{*} \triangle$ & $169.43 \pm 11.12^{*} \& \triangle$ & $157.27 \pm 8.51^{\& \#}$ & $149.85 \pm 8.90^{\& \#}$ \\
\hline & Hct (\%) & $43.42 \pm 2.71$ & $57.89 \pm 4.16^{*} \triangle$ & $49.13 \pm 3.10^{*} \& \triangle$ & $44.18 \pm 3.30^{\&}$ & $43.92 \pm 2.25^{\&}$ \\
\hline & $\mathrm{MCV}(\mathrm{fL})$ & $89.07 \pm 4.02$ & $95.59 \pm 12.14^{*}$ & $88.82 \pm 5.49^{\&}$ & $90.30 \pm 5.16^{\&}$ & $90.56 \pm 4.37^{\&}$ \\
\hline & $\mathrm{MCH}(\mathrm{pg})$ & $30.48 \pm 1.79$ & $35.58 \pm 3.14^{*} \triangle$ & $32.00 \pm 2.92^{*} \& \Delta$ & $32.70 \pm 2.35^{* \& \Delta}$ & $31.76 \pm 1.92^{*} \& \triangle$ \\
\hline & RDW (\%) & $13.48 \pm 0.81$ & $14.14 \pm 1.70$ & $12.91 \pm 0.58^{* \& \Delta}$ & $13.00 \pm 0.93^{* \&}$ & $13.08 \pm 0.69^{*} \&$ \\
\hline & WBC $\left(\times 10^{9}\right)$ & $5.47 \pm 1.07$ & $6.73 \pm 0.58^{\triangle}$ & $7.14 \pm 0.46^{*} \& \triangle$ & $5.64 \pm 0.78^{\& \#}$ & $5.22 \pm 0.93^{\& \#}$ \\
\hline & Neu (\%) & $52.89 \pm 3.27$ & $56.80 \pm 3.53$ & $65.80 \pm 3.27^{*} \triangle$ & $54.60 \pm 6.36^{\#}$ & $53.77 \pm 7.76^{\#}$ \\
\hline \multirow{8}{*}{$\begin{array}{l}\text { Control group } \\
(n=87)\end{array}$} & $\mathrm{RBC}\left(\times 10^{12}\right)$ & $5.12 \pm 0.24$ & $5.19 \pm 0.55$ & $5.18 \pm 0.15$ & $5.13 \pm 0.30$ & $5.09 \pm 0.24$ \\
\hline & $\mathrm{Hb}(\mathrm{g} / \mathrm{L})$ & $153.40 \pm 7.92$ & $154.94 \pm 6.08$ & $151.84 \pm 9.13$ & $154.75 \pm 4.31$ & $150.68 \pm 9.07$ \\
\hline & Hct (\%) & $43.34 \pm 2.56$ & $42.48 \pm 2.87$ & $43.46 \pm 2.43$ & $43.44 \pm 2.77$ & $42.90 \pm 2.29$ \\
\hline & $\mathrm{MCV}(\mathrm{fL})$ & $88.95 \pm 2.58$ & $90.18 \pm 2.76$ & $88.60 \pm 2.93$ & $89.45 \pm 2.88$ & $89.33 \pm 3.03$ \\
\hline & $\mathrm{MCH}(\mathrm{pg})$ & $30.16 \pm 2.09$ & $31.12 \pm 1.28$ & $29.73 \pm 2.01$ & $30.30 \pm 2.17$ & $30.55 \pm 1.39$ \\
\hline & RDW (\%) & $13.46 \pm 0.91$ & $13.36 \pm 0.70$ & $13.41 \pm 0.65$ & $13.48 \pm 1.00$ & $13.32 \pm 0.80$ \\
\hline & WBC $\left(\times 10^{9}\right)$ & $5.30 \pm 1.06$ & $5.53 \pm 1.07$ & $5.50 \pm 1.02$ & $5.51 \pm 1.09$ & $5.52 \pm 1.00$ \\
\hline & Neu (\%) & $55.36 \pm 8.81$ & $55.78 \pm 4.04$ & $57.63 \pm 5.46$ & $56.63 \pm 5.58$ & $57.14 \pm 4.05$ \\
\hline
\end{tabular}

Data are given as the mean $\pm \mathrm{SD}$. RBC = red blood cell, $\mathrm{Hb}=$ hemoglobin, $\mathrm{Hct}=$ hematocrit, $\mathrm{MCV}=$ mean corpuscular volume, $\mathrm{MCH}=$ mean corpuscular hemoglobin, $\mathrm{MCHC}=$ mean corpuscular hemoglobin concentration, RDW = red blood cell volume distribution width, WBC $=$ white blood cell, Neu = neutrophil. ${ }^{*} P<0.05$, relative to baseline, ${ }^{\&} P<0.05$, relative to high altitude values, ${ }^{\#} P<0.05$, relative to $3^{\text {rd }}$ day values, ${ }^{P} P<0.05$, relative to $50^{\text {th }}$ day values, ${ }^{\circ} P<0.05$, relative to the control group.

doi:10.1371/journal.pone.0062072.t007 
A.

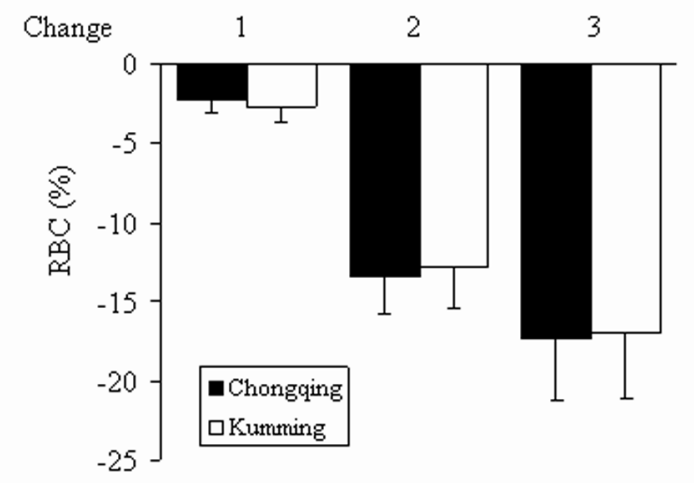

$\mathrm{C}$

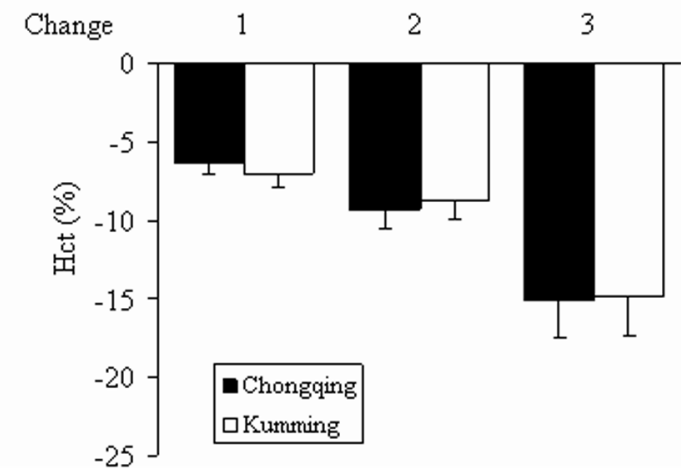

B

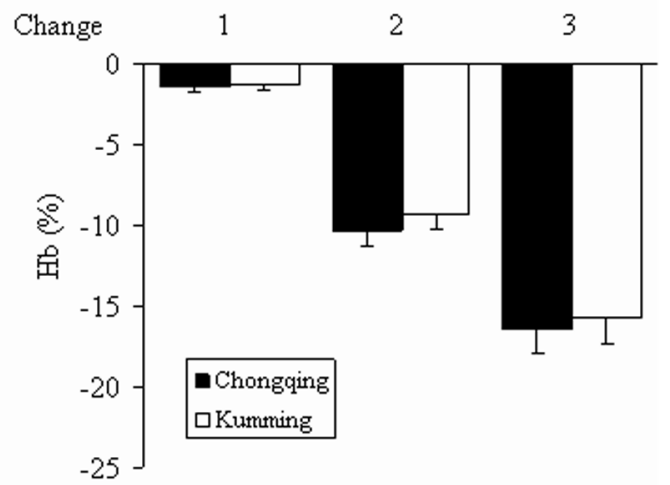

Figure 3. Rates of change of RBC, Hb, and Hct. Data are presented as mean \pm SD. The rate of change of (A) RBC, (B) Hb, and (C) Hct. Values recorded in subjects at high altitudes served as a baseline. Rate of change $1=$ (value on the 3rd day-value at high altitudes)/value at high altitudes $\times 100 \%$; rate of change $2=$ (value on the 50 th day-value at high altitudes)/value at high altitudes $\times 100 \%$, rate of change $3=$ (value on the 100th day-value at high altitudes)/value at high altitudes $\times 100 \%$. Rates of change 1,2 , and 3 showed no significant differences between the Chongqing and Kunming groups $(P>0.05)$.

doi:10.1371/journal.pone.0062072.g003

Rate of change in symptom scores ( 1 and 2) groups were not significantly different between the Chongqing and Kunming groups $(P>0.05)$. $\mathrm{Hb}$ and Hct showed similar tendencies in the two groups (Figure 3).

\section{Changes in CK, CK-MB, and LDH levels after the return}

Changes in CK, CK-MB, and LDH of subjects on the $3^{\text {rd }}, 50^{\text {th }}$, and $100^{\text {th }}$ days after the return to Chongqing and Kunming are illustrated in detail in Tables 8 and 9.
The levels of CK and CK-MB were significantly higher on the $3^{\text {rd }}$ day after the return than at baseline or at high altitudes $(P<0.05)$. Values were lower on the $50^{\text {th }}$ and $100^{\text {th }}$ day than on the $3^{\text {rd }}$ day $(P<0.05)$. No significant differences in $\mathrm{CK}$, CK-MB, or LDH were observed between baseline values and those recorded at high altitudes.

The levels of $\mathrm{LDH}$ were found to be significantly higher on the $3^{\text {rd }}$ and $50^{\text {th }}$ days than at baseline and or at high altitudes

Table 8. Serum CK, CK-MB, and LDH of subjects after returning to Chongqing.

\begin{tabular}{lllllll}
\hline Group & Parameter & Baseline & $\begin{array}{l}\text { High altitudes } \mathbf{6} \\
\text { months }\end{array}$ & $\mathbf{3}^{\text {rd }}$ day & $\mathbf{5 0}^{\text {th }}$ day & $\mathbf{1 0 0}^{\text {th }}$ day \\
\hline $\begin{array}{l}\text { HDAS group } \\
(\mathrm{n}=67)\end{array}$ & CK (IU/L) & $88.70 \pm 17.77$ & $92.90 \pm 21.80$ & $121.73 \pm 28.91^{* \& \Delta}$ & $97.57 \pm 21.91^{\#}$ & $94.02 \pm 18.20^{\#}$ \\
& CK-MB (IU/L) & $16.30 \pm 2.62$ & $16.50 \pm 3.59$ & $21.91 \pm 3.18^{*} \& \Delta$ & $17.63 \pm 3.23^{\#}$ & $15.80 \pm 4.61^{\#}$ \\
& LDH (IU/L) & $147.06 \pm 22.28$ & $151.98 \pm 34.40$ & $200.33 \pm 26.06^{*} \& \Delta$ & $177.18 \pm 31.87^{*} \& \# \Delta$ & $146.38 \pm 22.52^{\# *}$ \\
$\begin{array}{l}\text { Control group } \\
(\mathrm{n}=92)\end{array}$ & CK (IU/L) & $87.50 \pm 16.09$ & $91.37 \pm 17.95$ & $88.62 \pm 12.11$ & $91.50 \pm 18.64$ & $89.87 \pm 11.36$ \\
& CK-MB (IU/L) & $15.95 \pm 2.20$ & $14.76 \pm 2.25$ & $16.33 \pm 1.69$ & $15.74 \pm 1.91$ & $14.92 \pm 2.49$ \\
& LDH (IU/L) & $146.53 \pm 19.15$ & $151.16 \pm 16.95$ & $142.64 \pm 17.57$ & $152.69 \pm 18.17$ & $149.14 \pm 21.56$ \\
\hline
\end{tabular}

Data are given as the mean $\pm \mathrm{SD}$. CK $=$ creatine kinase, $C K-M B=$ creatine kinase-MB, LDH $=$ lactate dehydrogenase. ${ }^{*} P<0.05$, relative to baseline, ${ }^{\&} P<0.05$, relative to high altitude values, ${ }^{\#} P<0.05$, relative to $3^{\text {rd }}$ day values, ${ }^{\wedge} P<0.05$, relative to $50^{\text {th }}$ day values, $\triangle P<0.05$, relative to the control group.

doi:10.1371/journal.pone.0062072.t008 
Table 9. Serum CK, CK-MB, and LDH of subjects after returning to Kunming.

\begin{tabular}{|c|c|c|c|c|c|c|}
\hline Group & Parameter & Baseline & $\begin{array}{l}\text { High altitudes } 6 \\
\text { months }\end{array}$ & $3^{\text {rd }}$ day & $50^{\text {th }}$ day & $100^{\text {th }}$ day \\
\hline \multirow{3}{*}{$\begin{array}{l}\text { HDAS group } \\
(n=70)\end{array}$} & CK (IU/L) & $88.52 \pm 14.30$ & $90.63 \pm 20.70$ & $119.00 \pm 15.42^{*} \& \Delta$ & $96.36 \pm 18.96^{\#}$ & $90.36 \pm 14.37^{\#}$ \\
\hline & CK-MB (IU/L) & $15.04 \pm 1.38$ & $16.07 \pm 3.16$ & $21.41 \pm 3.26^{*} \& \Delta$ & $17.12 \pm 3.03^{\# \Delta}$ & $16.39 \pm 3.33^{\#}$ \\
\hline & LDH (IU/L) & $150.79 \pm 20.99$ & $153.44 \pm 26.42$ & $198.02 \pm 35.55^{*} \& \Delta$ & $176.41 \pm 26.94^{*} \& \# \Delta$ & $149.10 \pm 15.29^{\#^{\wedge}}$ \\
\hline \multirow{3}{*}{$\begin{array}{l}\text { Control group } \\
(n=87)\end{array}$} & CK (IU/L) & $90.96 \pm 21.89$ & $88.19 \pm 21.06$ & $90.74 \pm 18.24$ & $86.03 \pm 14.74$ & $93.15 \pm 15.55$ \\
\hline & CK-MB (IU/L) & $15.09 \pm 2.48$ & $15.50 \pm 2.35$ & $15.71 \pm 3.36$ & $15.53 \pm 2.94$ & $14.90 \pm 3.04$ \\
\hline & LDH (IU/L) & $148.72 \pm 17.78$ & $150.16 \pm 20.56$ & $147.29 \pm 18.50$ & $152.73 \pm 18.93$ & $150.75 \pm 19.20$ \\
\hline
\end{tabular}

Data are given as the mean \pm SD. $C K=$ creatine kinase, $C K-M B=$ creatine kinase-MB, LDH = lactate dehydrogenase. ${ }^{*} P<0.05$, relative to baseline, ${ }^{\&} P<0.05$, relative to high altitude values, ${ }^{\#} P<0.05$, relative to $3^{\text {rd }}$ day values, ${ }^{\wedge} P<0.05$, relative to $50^{\text {th }}$ day values, ${ }^{\triangle} P<0.05$, relative to the control group.

doi:10.1371/journal.pone.0062072.t009

$(P<0.05)$. Their values were significantly lower, approaching baseline, on the $100^{\text {th }}$ day than on the $3^{\text {rd }}$ and $50^{\text {th }}$ days $(P<0.05)$.

Compared with control group, $\mathrm{CK}$ and $\mathrm{CK}-\mathrm{MB}$ were higher on the High altitude 6 months and $3^{\text {rd }}$ day after the return in HDAS group (both $P<0.05$ ). The levels of $\mathrm{CK}-\mathrm{MB}$ were found to be significantly higher on the $50^{\text {th }}$ days than control group in Kunming $(P<0.05)$. The levels of $\mathrm{LDH}$ were found to be significantly higher on the high altitudes 6 months, $3^{\text {rd }}$ and $50^{\text {th }}$ days in HDAS group than in control group $(P<0.05)$.
Rates of change rate 1,2, and 3 were not significantly different between the Chongqing and Kunming groups $(P>0.05)$. CK-MB and LDH showed similar tendencies (Figure 4).

\section{Discussion}

More studies of high altitude de-acclimatization syndrome of subjects who visit high-altitude areas are necessary. Improvements in the transportation system in Tibet and Qinghai, the development of tourism and resources in these areas, and improvements in the conditions for the construction of manufacturing facilities have
A

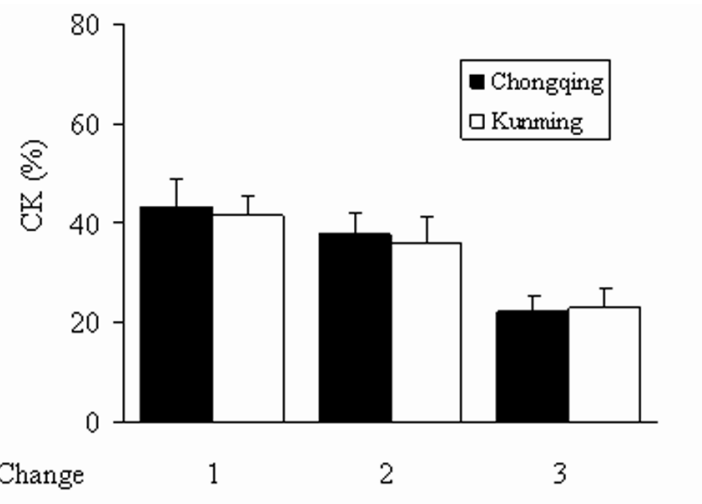

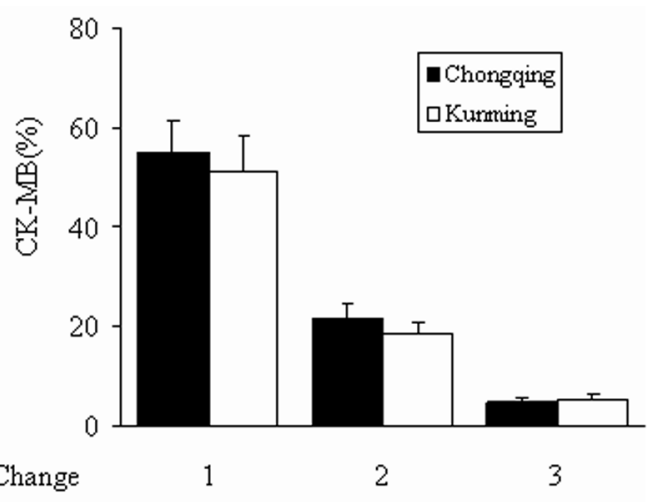

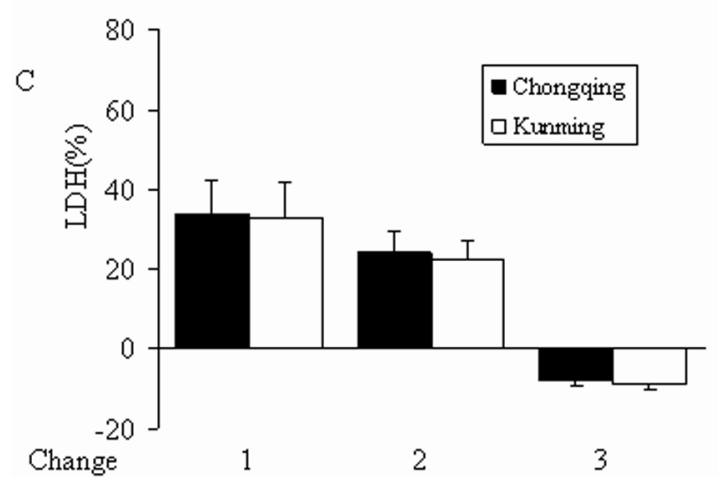

Figure 4. Rates of change of CK, CK-MB, and LDH. Data are presented as mean \pm SD. The rate of change rate of (A) CK, (B) CK-MB, (C) LDH. Values recorded in subjects at high altitudes served as the baseline. Rate of change $1=$ (value on 3rd day-value at high altitudes)/value at high altitudes $\times 100 \%$; rate of change $2=$ (value on 50 th day-value at high altitudes)/value at high altitudes $\times 100 \%$; rate of change $3=($ value at 100 th dayvalue at high altitudes)/value at high altitudes $\times 100 \%$. Rates of change 1, 2, and 3 were not significantly different between the Chongqing group and Kunming group $(P>0.05)$.

doi:10.1371/journal.pone.0062072.g004 
increased the number of people who come to these high-altitude plateau areas for work and travel, usually for several months or one year, after which they return home. These visitors come from all over the world, not only from within China. These temporary residents typically show the following two distinct features. The first is that they tend to be adults between 15 and 70 years old. Among working populations, the majority are young and middleaged (20-50 years old). The other is that they typically remain at high altitudes for only short periods of time ( $\leq 1$ year). This includes people who work at high altitudes for half a year to one year and then return to low-altitude areas. There have been studies on high-altitude de-acclimatization syndrome and relevant diagnostic criteria, but most of them have focused on individuals who lived at high altitudes for long periods of time (over 5 years, up to 20 years) $[16,20]$. Current studies on individuals who return to low altitude areas after fixed time exposure to high altitudes are still rare.

The establishment of diagnostic criteria for high-altitude deacclimatization syndrome after fixed time exposure to high altitudes is crucial to prevention and treatment. The present study focused on symptoms of high-altitude de-acclimatization among 136 subjects who worked in the Tibetan plateau ( $\geq 3600 \mathrm{~m})$ about half a year between 2009 and 2010 and returned to Chongqing and Kunming afterwards. It also discusses diagnostic criteria suitable for use with high-altitude de-acclimatization after a fixed time ( $\leq 1$ year) of exposure to high altitudes. Our epidemiological data showed that, upon returning to lowlands or plains, subjects exhibited the following symptoms: fatigue, sleepiness, insomnia, unresponsiveness, memory loss, fidgetiness, headache, throat pain or discomfort, coughing, expectoration, chest tightness, flustering, increased appetite, decreased appetite, constipation, diarrhea, abdominal distention, abdominal pain, lumbago, and arthralgia. Other symptoms of discomfort typically found in long-term visitors to high altitudes upon their return to lowland areas, such as numbness in all acroanesthesia, cardiodynia, slowed pulse, lower extremity edema, facial swelling, and cyanosis, were not observed. Absence of these symptoms in high-altitude visitors might be due to the fact that the damage to their hearts and lungs that occurred after their return to lowland areas was not severe. The duration and severity of the influences of environmental factors such as hypoxia and cold are here proposed as modified diagnostic criteria for a fixed time de-acclimatization syndrome. This may facilitate understanding, diagnosis, and treatment of high-altitude deacclimatization among people who visit high-altitude areas for fixed times of time, benefiting the physical health, mental health, and quality of life of individuals who temporary work on the Tibetan plateau and then return to lowland plains. It may also support further in-depth investigations of the pathogenesis of highaltitude de-acclimatization after exposure to high-altitude environments.

Evaluation of the de-acclimatization syndrome is key to establishing diagnostic criteria. Symptoms of 136 subjects who returned to low altitude upon exposure of high altitudes 6 months were evaluated in this project. Until the 3rd day after each person's return, the symptoms of high-altitude de-acclimatization remained steady. Both symptom scores and incidence of each symptom decreased on the $50^{\text {th }}$ day, and then decreased further on the $100^{\text {th }}$ day. We speculate that it may be associated with the attenuation of damage from low-altitude re-acclimazation and reoxygenation. In previous study, we surveyed personnel who performed earthquake relief work at Yushu in Qinhai and followed up with them for 120 days after they returned to lowland plains areas. These individuals showed symptoms of discomfort, including dizziness, fatigue, sleepiness, and other symptoms, and the rate of occurrence was as high as $100 \%$ [23]. Studies conducted in other countries have shown that mountain climbers returning to lowland areas also show some symptoms of deacclimatization, in this case called "oxygen intoxication syndrome." Specifically, they feel top-heavy and sleepy, and they fall asleep easily and become hard to wake up, as if they were drunk. The present study showed that, upon exposure to the lowland $\mathrm{O}_{2}$ levels, which can reach $21 \%$, reoxygenation proceeded, and the blood oxygen level increased by $6-8 \%$ after the return. Other studies have shown that, after high-altitude visitors return to lowlands; their red blood cells remain capable of carrying high amounts of oxygen, which leads to increased blood oxygen content and pleonastic blood [14]. This causes reoxygenation of the body after hypoxia, which can induce the activation of many signal pathways in neuronal cells, myocardial cells, endothelial cells, and small intestine tissues and induce apoptosis and damage to these cells $[22,24-30]$. We believe that the occurrence of high-altitude de-acclimatization is closely related to reoxygenation. Some believe that the damage to organs, such as the brain, observed after the subjects returned to lowland plains were a continuation of damage caused by hypoxia at high altitudes [31-33]. However, studies on populations with high-altitude de-acclimatization conducted by our group and by Cui's group have shown that none of the symptoms of de-acclimatization are observable while the subjects are still in the high-altitude environment $[15,16]$. This suggested that high-altitude de-acclimatization syndrome may not be directly related to hypoxia-induced damage. The results of the present study also showed that the overall symptom scores of subjects returning to Kunming were lower than those returning to Chongqing at all points in time. On the 3rd day after their return, the rate of occurrence of each symptom among subjects returning to Kunming was also significantly lower than among subjects returning to Chongqing. This suggests that the severity of highaltitude de-acclimatization and the rate of occurrence of related symptoms may be correlated with the difference in altitude between the high-altitude area and the area to which the subjects returned.

In addition, we observed that physiological condition of 41 subjects (21 subjects from Chongqing and 20 from Kunming) after returned to low altitude from 1 st day to 1 week. Immediately upon returning to low-altitude areas, subjects felt excited and comfortable, breathed smoothly, and enjoyed good appetite. Few subjects complained of fatigue. The next day, many people began to show some symptoms, including fatigue, headache, dizziness, sleepiness, insomnia, unresponsiveness, memory loss, agitation, sore throat, coughing, expectoration, chest tightness, increased appetite, reduced appetite, abdominal distension, diarrhea, and unexplained joint pain. On the third day, most subjects' symptoms were worse than on the $2^{\text {nd }}$ day. The symptom scores had not changed significantly by the $5^{\text {th }}$ and $7^{\text {th }}$ days compared to the $3^{\text {rd }}$ day. Indeed, few subjects' symptoms improved and disappeared on $3^{\text {rd }}$ day.

Hematological testing is an indispensable auxiliary tool in the diagnosis of high-altitude de-acclimatization syndrome. The present study showed that on $3^{\text {rd }}$ day after the subjects' return to lowlands, the subjects' $\mathrm{RBC}, \mathrm{Hb}$, and Hct levels were significantly lower than they had been at high altitudes but still higher than baseline. On the 50th day after the return, the values of these indices were no longer different from baseline.Hypoxia causes RBC, $\mathrm{Hb}$, and Hct levels to increase significantly after individuals ascend to high altitudes. They stabilize at relatively high levels [14]. When these individuals return to lowlands, RBC, $\mathrm{Hb}$, and Hct all gradually returned to baseline or even dropped below baseline $[34,35]$. However, the time required for these 
indices to return to baseline may vary due to differences in the duration of exposure to high altitudes, the altitude of the plateau area, and the intensity of labor performed at high altitudes. $\mathrm{Hb}$ and Hct levels might recover in 1 day or take as long as 61 days [3,35-38]. We speculate that it may be associated with that reexpansion of plasma volume to reverse the hemoconcentration, prevention of recruitment of new erythrocytes by down-regulating erythropoiesis and destruction of excess erythrocytes, recycling of $\mathrm{Hb}$, and re-uptake of erythrocytes by the spleen.

Myocardial zymography is an important parameter in the evaluation of damage to the heart muscles of subjects with highaltitude de-acclimatization syndrome. The results of the present study showed that, in both studied populations, the CK, CK-MB, and LDH levels did not differ significantly from baseline after 6 months of exposure to high altitudes. On the $3^{\text {rd }}$ day after the return to lowland areas, the CK, CK-MB, and LDH levels were significantly higher than baseline. On the $50^{\text {th }}$ day, CK and CKMB levels were not significantly different from baseline. On the $100^{\text {th }}$ day, the LDH levels were not significantly different from baseline. These data suggest that reoxygenation activates multiple pathways that induced the damage of the heart muscles [27]. This increase the expression of $\mathrm{CK}, \mathrm{CK}-\mathrm{MB}$, and $\mathrm{LDH}$ in the plasma, as the body transitions from a hypoxic state to a reoxygenated one. On the other hand, parameters become gradually normalised, myocardial damage was improvement because of sea level reacclimatization.

The rates of improvement in the subjects' symptoms and the rates of change in $\mathrm{RBC}, \mathrm{Hb}$, Hct, $\mathrm{CK}, \mathrm{CK}-\mathrm{MB}$, and $\mathrm{LDH}$ levels were not significantly different between individuals who returned to Kunming and those who returned to Chongqing, suggesting that the rate of recovery may not be related to the altitude of the area to which the sbujects returned. The underlying cause of this remains unclear. However, neutrophil granulocytes were found to play an important role in the non-specific cellular immune system of the blood. On the $3^{\text {rd }}$ day after the return, the relative white

\section{References}

1. MacNutt MJ (2011) Acclimatisation, de-acclimatisation and re-acclimatisation to hypoxia. Vancouver: School of Human Kinetics, Ph.D. Dissertation, University of British Columbia. pp16-23.

2. Ward RO (1908) Alveolar air on monte rosa. J Physiol 37: 378-389.

3. Savourey G, Garcia N, Besnard Y, Guinet A, Hanniquet AM, et al. (1996) Preadaptation, adaptation and de-adaptation to high altitude in humans: cardioventilatory and haematological changes. Eur J Appl Physiol Occup Physiol 73: 529-535.

4. Katayama K, Sato K, Matsuo H, Ishida K, Iwasaki K, et al. (2004) Effect of intermittent hypoxia on oxygen uptake during submaximal exercise in endurance athletes. Eur J Appl Physiol 92: 75-83.

5. Heinicke K, Prommer N, Cajigal J, Viola T, Behn C, et al. (2003) Long-term exposure to intermittent hypoxia results in increased hemoglobin mass, reduced plasma volume, and elevated erythropoietin plasma levels in man. Eur J Appl Physiol 88: 535-543.

6. Song Rf, Liu BZ, Zhang SL, Yang TL, Jiang XF, et al. (1994) An investigation of acclimatization of high altitude immigrants descending plain for a short-term. Journal of nanjing railway medical collge 13: 207-210.

7. Richalet JP, Donoso MV, Jimenez D, Antezana AM, Hudson C, et al. (2002) Chilean miners commuting from sea level to $4500 \mathrm{~m}$ : a prospective study. High Alt Med Biol 3: 159-166.

8. Boning D, Maassen N, Jochum F, Steinacker J, Halder A, et al. (1997) Aftereffects of a high altitude expedition on blood. Int J Sports Med 18: 179-185.

9. Risso A, Turello M, Biffoni F, Antonutto G (2007) Red blood cell senescence and neocytolysis in humans after high altitude acclimatization. Blood Cells Mol Dis 38: 83-92.

10. Hansen J, Sander M (2003) Sympathetic neural overactivity in healthy humans after prolonged exposure to hypobaric hypoxia. J Physiol 546: 921-929.

11. Savourey G, Garcia N, Caravel JP, Gharib C, Pouzeratte N, et al. (1998) Preadaptation, adaptation and de-adaptation to high altitude in humans: hormonal and biochemical changes at sea level. Eur J Appl Physiol Occup Physiol 77: 3743.

12. Cavaletti G, Tredici G (1993) Long-lasting neuropsychological changes after a single high altitude climb. Acta Neurol Scand 87: 103-105. blood cell and neutrophil granulocyte counts were significantly higher than baseline. This may be related to hypoxia/reoxygenation-induced tissue damage and the release of inflammatory mediators [39].

Our study has some limitations. (1) It was not a randomized multicenter study. (2) The regions to which the subjects returned included only two areas and these areas are not representative of all visitors to the plateau. (3) The subjects' ages were only representative of some visitors. (4) All subjects were men and most of them were from 25 to 45 years old. (5) Several factors could not be controlled well between Lhasa and low-altitude areas. For instance, the time zone is different, the types of meat the subjects ate were different, and different rest-time activities were available at Lhasa than at low altitudes. (6) The present study is a preliminary study and it requires only a basic framework for the diagnosis of high-altitude de-acclimatization syndrome conditions.

\section{Conclusions}

In conclusion, in the present study, we established diagnostic criteria and symptom evaluation criterion for high-altitude deacclimatization in individuals returning to lowlands after exposure to high altitudes lasting less than 1 year. We evaluated the associations between symptom scores and differences in altitude, symptom characteristics, hematological cell levels, blood-gas levels, and myocardial enzyme levels. All values slowly returned to baseline. However, recovery from de-acclimatization syndrome was found to take a long time, more than 100 days.

\section{Author Contributions}

Conceived and designed the experiments: GW. Performed the experiments: BH JW XQ ZW JL YC HC QZ. Analyzed the data: GQ MH QZ GW. Contributed reagents/materials/analysis tools: BH ZW JL. Wrote the paper: BH GW. Approved the final manuscript: BH JW GQ MH XQZW JL YC HC QZ GW.

13. Bao M, Engel SA (2012) Distinct mechanism for long-term contrast adaptation. Proc Natl Acad Sci U S A 109: 5898-5903.

14. Zubieta-Calleja G (2010) Human adaptation to high altitude and to sea level: acid-base equilibrium, ventilation and circulation in chronic hypoxia. VDM publisher, pp 38-45.

15. Cui SZ, Tang SY, Wu YA, Niu WZ (1998) The high altitude de-acclimatization symptom investigation of 626 cases Tibetan settlers after return to sea level. Medicial Journal of National Defending Forces in Southwest China 8: 2.

16. Zhou OO Yang SY, Yuan ZC, Wang YH, Zhang XF, et al. (2012) A research in diagnostic criteria of high altitude de-adaptation for plateau migrants returning to the plains:a multicenter, randomized controlled trial. Medical Journal of Chinese People's Liberation Army 37: 146-155.

17. Zhang HY, Zhang YX, Yang ZX, Huang P, Wang FF, et al. (2012) High altitude acclimatization and de-acclimatization. Chin J Appl Physiol 28: 94-96.

18. Zhang YB, Wang Y, Liu XL, Fen GH, Zhao DY (1996) People and high altitude. Xining: Qinghai People's Publishing House. pp 297-319.

19. Gao YQ (2005) High altitude military medicine. Chongqing: Chongqing Publishing House. pp 237-238.

20. Shi ZF, Zhou QQ Xiang L, Ma SD, Yan CJ, et al. (2011) Three preparations of compound Chinese herbal medicines for de-adaptation to high altitude: a randomized, placebo-controlled trial. Zhong Xi Yi Jie He Xue Bao 9: 395-401.

21. Zhang XZ, He FW, Kang XW, Ma Y, Zhou ZJ (1994) The study of RBC-SOD and GSH-PX of subjects from high altitude to sea level. Chinese journal of internal mendicine 33: 1 .

22. Tagami M, Yamagata K, Ikeda K, Nara Y, Fujino H, et al. (1998) Vitamin E prevents apoptosis in cortical neurons during hypoxia and oxygen reperfusion. Lab Invest 78: 1415-1429.

23. Shi ZF, Zhou QQ, Ma SD, Yan CJ, Xiang L (2011) Investigation of high altitude de-accliamziton in the earthquest relief unit. Journal of Preventive Medicine of Chinese People's Liberation Army 29: 114-115.

24. Shi Y, Deng NW, Chen DL, Qi L, Liu BZ, et al. (1991) The change of cadiovascular function in high altitude acclimatization and de-acclimatization. Chinese Journal of Applied Physiology 7: 4.

25. Terada LS (1996) Hypoxia-reoxygenation increases O2-efflux which injures endothelial cells by an extracellular mechanism. Am J Physiol 270: H945-950. 
26. Li C, Jackson RM (2002) Reactive species mechanisms of cellular hypoxiareoxygenation injury. Am J Physiol Cell Physiol 282: C227-241.

27. Ngoh GA, Facundo HT, Hamid T, Dillmann W, Zachara NE, et al. (2009) Unique hexosaminidase reduces metabolic survival signal and sensitizes cardiac myocytes to hypoxia/reoxygenation injury. Circ Res 104: 41-49.

28. Ban K, Kozar RA (2012) Protective role of p70S6K in intestinal ischemia/ reperfusion injury in mice. PLoS One 7: e41584.

29. Kambara T, Ohashi K, Shibata R, Ogura Y, Maruyama S, et al. (2012) CTRP9 protein protects against myocardial injury following ischemia-reperfusion through AMP-activated protein kinase (AMPK)-dependent mechanism. J Biol Chem 287: 18965-18973.

30. Ma X, Liu H, Foyil SR, Godar RJ, Weinheimer CJ, et al. (2012) Impaired autophagosome clearance contributes to cardiomyocyte death in ischemia/ reperfusion injury. Circulation 125: 3170-3181.

31. Hornbein TF (2001) The high-altitude brain. J Exp Biol 204: 3129-3132.

32. Joanny P, Steinberg J, Robach P, Richalet JP, Gortan C, et al. (2001) Operation Everest III (Comex'97): the effect of simulated sever hypobaric hypoxia on lipid peroxidation and antioxidant defence systems in human blood at rest and after maximal exercise. Resuscitation 49: 307-314
33. Neubauer JA (2001) Invited review: Physiological and pathophysiological responses to intermittent hypoxia. J Appl Physiol 90: 1593-1599.

34. Meyer LB, Pace N, Vaughan BE (1956) Erythrolysis on return of altitude acclimatized individuals to sea level. J Appl Physiol 9: 141-144.

35. Svedenhag J, Piehl-Aulin K, Skog C, Saltin B (1997) Increased left ventricular muscle mass after long-term altitude training in athletes. Acta Physiol Scand 161: 63-70.

36. Dill DB, Horvath SM, Dahms TE, Parker RE, Lynch JR (1969) Hemoconcentration at altitude. J Appl Physiol 27: 514-518.

37. Buderer MC, Pace N (1972) Hemopoiesis in the pig-tailed monkey Macaca nemestrina during chronic altitude exposure. Am J Physiol 223: 346-352.

38. Gunga HC, Rocker L, Behn C, Hildebrandt W, Koralewski E (1996) Shift working in the Chilean Andes $(>3,600 \mathrm{~m})$ and its influence on erythropoietin and the low-pressure system. J Appl Physiol 81: 846-852.

39. Stice JP, Chen L, Kim SC, Jung JS, Tran AL, et al. (2011) 17beta-Estradiol, aging, inflammation, and the stress response in the female heart. Endocrinology 152: $1589-1598$ 